\title{
Right thyroidectomy assisted by transaxillary-areolar approach
}

\author{
Torroella $A^{1 *}$, Muniesa-Gallardo $C^{2}$, Vogel $V^{3}$ and Vidal $\mathrm{O}^{1}$ \\ ${ }^{1}$ Hospital Clínic, Barcelona, Spain \\ ${ }^{2}$ Hospital de La Fe, Valencia, Spain \\ ${ }^{3}$ Universitäsklinkum Gießen, Marburg, Germany
}

A 58-years-old woman diagnosed of right toxic thyroid nodule, measuring $21 \times 17 \times 30 \mathrm{~mm}$, compatible with Bethesda IV in cytological results. She is proposed for right thyroidectomy by right transaxyloareolar approach. A $12 \mathrm{~mm}$ trocar is placed at the lateral mammary sulcus, for $0^{\circ}$ optics. Next, a $5 \mathrm{~mm}$ trocar is placed under direct vision at the superior periareolar level and another $5 \mathrm{~mm}$ trocar in the anterior axillary line. Attached images show trocars disposition, as well as the transluminescence secondary to the dissection of the cervical subcutaneous space (Figure 1). Aesthetic result on the 7 th postoperative day [1-3] (Figure 2).

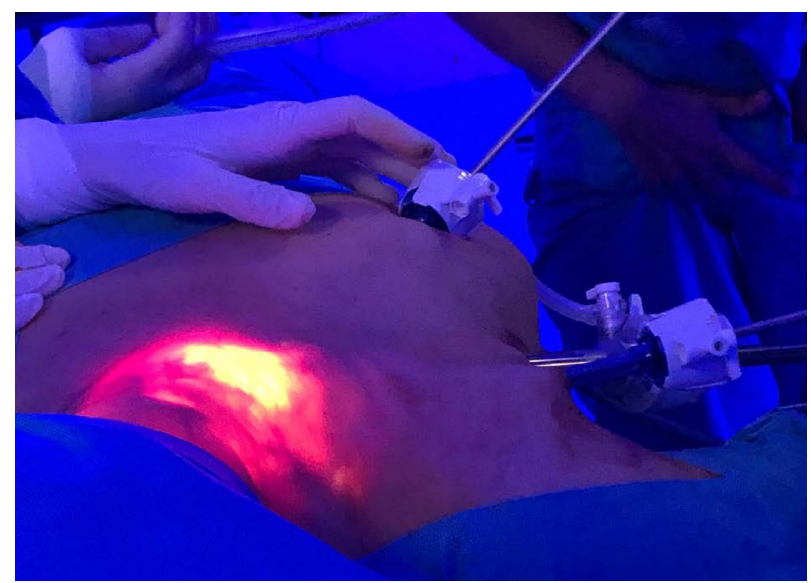

Figure 1. Transluminescence secondary to the dissection of the cervical subcutaneous space

Copyright: (C2018 Torroella A. This is an open-access article distributed under the terms of the Creative Commons Attribution License, which permits unrestricted use, distribution, and reproduction in any medium, provided the original author and source are credited.

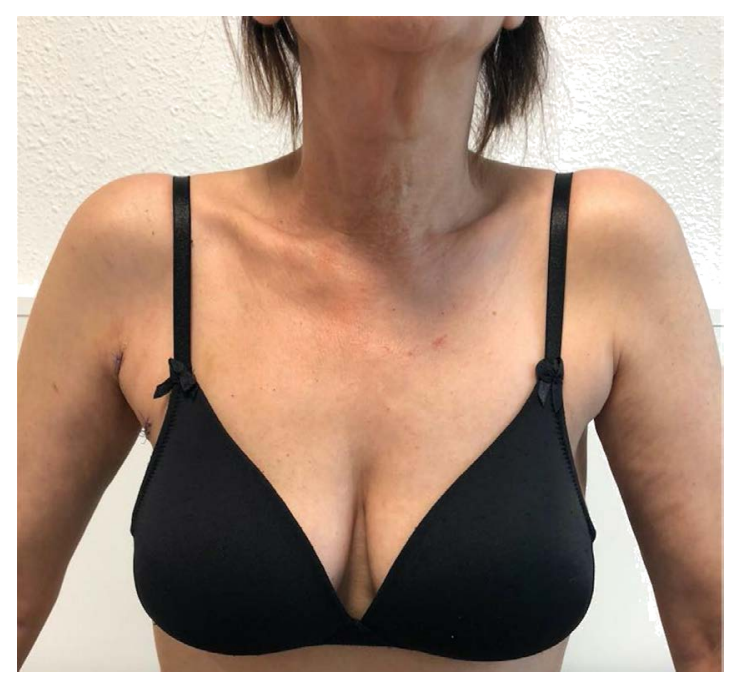

Figure 2. Aesthetic result on the 7th postoperative day

\section{References}

1. Bhargav PR, Amar V (2013) Operative technique of endoscopic thyroidectomy: a narration of general principles. Indian J Surg 75: 216-219. [Crossref]

2. Russell JO, Noureldine SI, Al Khadem MG, Tufano RP (2016) Minimally invasive and remote-access thyroid surgery in the era of the 2015 American Thyroid Association guidelines. Laryngoscope Investig Otolaryngol 1: 175-179. [Crossref]

3. Huang JK, Ma L, Song WH, Lu BY, Huang YB, et al. (2016) Quality of life and cosmetic result of single-port access endoscopic thyroidectomy via axillary approach in patients with papillary thyroid carcinoma. Onco Targets Ther 9: 4053-4059. [Crossref] 